\title{
Analysis of falls in different rounds of the supercross world cup in the netherlands and belgium
}

\author{
Luciano B Leite. ${ }^{1} \bowtie$, Pedro P. Pussieldi ${ }^{1}$, Guilherme A Pussieldi ${ }^{1}$
}

\begin{abstract}
The study aimed to verify the number of falls of men and women during the two rounds of the Supercross BMX Cycling World Cup in the Netherlands and Belgium in 2017, and check which straight have the most falls. And, also, to verify if there is difference between the circuits in relation to the number of falls of the athletes in these two competitions. For this, an analysis of the official two-rounds films of the BMX Cycling World Cup Supercross in 2017 was carried out in Papendal (Holland) and Zolder (Belgium) in May 2017. The number of falls of the athletes was analyzed by observing and counting the number of these. A total of 189 male and 45 female athletes participated in the study, and all the two events were analyzed, verifying in which straight the falls occurred. It is possible to conclude the second straight in both straights was the one that presented more number of falls, and the track of Belgium presented more number of falls.
\end{abstract}

Keywords: Falls; BMX Cycling; BMX Track; High Performance

$\triangle$ Contact email: guilhermepussieldi@ufv.br (G Pussieldi)

${ }^{1}$ Viçosa Federal University - Campus de Florestal, Biological Science and Health Institute

Received: 03 September 2018. Accepted: 26 November 2018.

\section{Introduction}

In the mid-1960s, between New York and California in the United States, motocross was beginning to dawn, gaining many supporters of the sport, later inspiring countless young people around the 1970 s to use common bicycles, creating dirt tracks with various obstacles, promoting several meetings between them, thus the Bicycle Motocross or BMX born (Bitencourt and Amorim, 2006).

The sport involves features of cycling and motocross on dirt tracks where athletes reach a high speed during the races. Over the years, several adaptations of the common bicycles were necessary, and the North American factories created the BMX (small bicycle, rim 20, suitable for practicing Bicicross) in 1978, when the focus of the sport was to reach the youth public and design internationally, attracting young people through the novelty of the maneuvers during the tests and the various obstacles of the tracks (Bitencourt and Amorim, 2006).

The sport has won countless practitioners, becoming one of the most practiced sports by the youth, in 2004 received the title of Olympic sport, in the modality BMX Race, practiced in natural area (Bitencourt and Amorim, 2006; Rodrigues, 2010). BMX is an individual sport of open ability, with several conditions that vary from track to track, which require constant adaptations by the competitors, also having physical contact between them
(Zabala et al., 2008). aerobic and mainly anaerobic conditioning (Louis et al., 2013).

BMX has been part of the official competition of the Olympic Games since Beijing 2008. It is a sport practiced with special bicycles, where races are made on dirt tracks and curves on land or asphalt, ranging in length from 300 to 400 meters. In these competitions the average time is around 30 to 45 seconds and depends on the characteristics and layout of the slopes for longer or shorter durations, but the average does not exceed this duration (Cowell Cronin and Mcguican, 2011). Circuits that are short, as described above, depending on their characteristics and their obstacles, and are performed in high intensity with anaerobic predominance. BMX tests are performed in eight-competitor batches, where the top four qualify for the next stage up to the final, which is also performed with eight competitors (Campillo, Doremus and Hespel, 2007). It is a sport practiced on

Table 1. Cycling power output: comparison of Stages and PowerTap powermeter.

\begin{tabular}{ccccc} 
& \multicolumn{2}{c}{ Men } & \multicolumn{3}{c}{ Women } \\
& Netherlands & Belgium & Netherlands & Belgium \\
\hline $\begin{array}{c}1 \text { st } \\
\text { Straight } \\
\text { 2nd }\end{array}$ & 15 & 31 & 4 & 5 \\
$\begin{array}{c}\text { Straight } \\
\text { 3rt }\end{array}$ & 20 & 37 & 4 & 6 \\
$\begin{array}{c}\text { Straight } \\
4 \text { th }\end{array}$ & 4 & 13 & 4 & 5 \\
$\begin{array}{c}\text { Straight } \\
\text { Total }\end{array}$ & 6 & 3 & 0 & 0 \\
\hline \\
\% Falls & $28 \%$ & 84 & 12 & 16 \\
\hline
\end{tabular}


small bikes that allow the competitor to gain a greater acceleration and precision when compared to a normal bike, besides high speed in small overtaking spaces (Campillo, Doremus and Hespel, 2007). Therefore, it is also a dangerous sport, where there are numerous falls during the batteries, as in the case of the Olympic Games in Rio in 2016, which presented the highest number of medical care for injuries compared to other modalities (Soligart et al., 2017). The objective of this paper is to verify the number of falls of men and women during two rounds of the Supercross BMX Cycling World Cup of the Netherlands and Belgium in 2017, and to check which straight have the highest number of falls. Also, check if there is a difference between the circuits in relation to the number of falls of the athletes in these two competitions.

\section{Methods}

This was a cross-sectional, retrospective study with data obtained through official filming of the Union Cycliste Internationale (UCI), in two rounds of the BMX Cycling World Cup, Supercross modality, in 2017 (UCI, 2017). Competitions held in the city of Papendal (Holland) and Zolder (Belgium), in May 2017.

We analyzed the number of falls of the athletes in the round of BMX cycling of the Netherlands and in the second the number of falls of the round of Belgium. This analysis was done by observing and counting the number of falls verified in the official film of the event.

In the race in the Netherlands 176 male and 45 female athletes participated. In the competition in Belgium, 189 men and 46 women participated, and $93 \%$ and $98 \%$ of men and women, respectively, participated in both competitions, in the Netherlands and Belgium.

For the competition held in the Netherlands, 156 male and 48 female races were analyzed, verifying in which straight of the four on the BMX circuit the falls occurred. For Belgium, the number of videos analyzed was 182 races for men and again 98 for women, distributed in the qualifying and final stages. In these phases, the number of athletes per test varied from 6 to 8 athletes per race.

A descriptive analysis of the falls was made, verifying in which straight these accidents occurred. This analysis required at least three views per race, needing to return the film a few times. It was also compared if there are differences between the number of falls per straight and which circuit has the highest number of falls.

\section{Results}

It can be observed in Table 1 that the Belgian track had the highest number of falls for both men and women, with men having an $87 \%$ increase in the number of falls, from 45 falls to 84 . The women had an increase of $33 \%$, going from 12 to 16 falls.

The straight that presented the most falls for the men was the 2nd straight on both tracks. And for women only in Belgium that the second straight was the highest number of falls, but there were no accidents for women in the 4th straight.
When comparing the number of falls for men, it can be verified that the second straight, in the two tracks, showed the highest number of accidents, with $45 \%$ and $44 \%$ of them, both in the Netherlands and in Belgium (Figure 1 and 2). Straights 3 and 4 were the ones with the lowest number of falls in both tracks. The last straight on the Belgian track had fewer accidents compared to all others on both tracks for men.

In the comparison between women and between tracks, a balance is found for the percentage of accidents, for the 2,3 and 4 straights, both in the Netherlands and in Belgium, despite the small difference in the number of falls in the second straight line. Zolder track in Belgium (Figures 3 and 4). In the same way, it was verified that in the last straight of the tracks, there were no falls of the women.

$6.1 \%$ for SCP and PT express mean variation of PO, whereas determination of cadence caused CVs of $10.3 \%$ and $10.2 \%$ respectively.

\section{Discussion}

When you look at the difference between the tracks, it was found that the Belgian track in Zolder showed the highest number of falls in relation to the Papendal track in the Netherlands. However, BMX sport is a risk sport, its number of falls has always been considered high in most competitions (Engebretsen et al., 2013, Soligard et al., 2017). This difference between the number of falls between tracks may be due to the fact that each BMX track presents a difference in the number of ramps, the distance between them and the degree of difficulty for each obstacle, as seen in the study by Mateo-March et al. (2012). The same authors identified that the tracks of the same models of our study, Supercross type, present a great component of techniques during the flights and enormous technical complexity in the modality, in relation to tracks where the continental and national championships are realized (Mateo-March et al., 2012). This technical complexity is also reported in the study by Keogh, Haakonsen and Orr (2017), who state that the start in these tracks requires the need for a very accurate understanding for a better performance.

The fall is very common in BMX cycling (Heggie and Caine, 2012; Engebretsen et al., 2013; Soligard et al., 2017). However, it is not a modality that presented more injuries during the Rio de Janeiro Olympic Games in 2016 (Guermazi et al., 2018), despite having the sporting modality that most had medical / outpatient care at these Olympic Games (Soligard et al. , 2017), with a 6-fold increase over the 1989 European Championship (Brogger-Jensen, Hvass and Bugge, 1990), taking into account that the tracks used in the different competitions have distances between ramps, angles of obstacles and complexity of different overruns (Mateo-March et al., 2012).

During the 2016 Olympic Games in Rio de Janeiro, there were no BMX cycling, muscular injuries, stress fractures, or tendon injuries, but fractures in a total of two, one in the lower limbs and the other in the upper limbs (Guermazi et al., 2017) This data was lower than 
the Road Cycling, which presented four fractures during the games, according to the same authors who analyzed the data made available by the service of diagnostic images of the event during the competition.

In the reported studies of Engebretsen et al. (2013) and Soligard et al. (2017) were not indicated in which position of the lane occurred the falls, different from our work, where it was verified that the second straight was the most presented more falls for the men, in both tracks, and for the women only in the runway of the Belgiam, that the second straight was bigger in number of falls, however the women did not present falls in the 4th straight. This fact may be due to the low speed that women can achieve in relation to men (Cowell, Mcguigan and Cronin, 2012).

Regarding the percentage of number of falls, for men, it can be verified that the second straight, in the two tracks was the one that presented the highest number of accidents, whereas for the women the straight did not present any discrepancies in relation to the number of accidents. This result may also be due to the fact that the velocity during the displacement of the women is smaller than in the men (Cowell, Mcguigan and Cronin, 2012), and this reduces the possibility of accidents. However, the percentage of number of falls on the track of the Netherlands between men and women was very close, 28 and $25 \%$ respectively. But on the Belgian track, the percentage of men fall was much higher, with 53\% against 33\% for women.

Huh (2017) points out that Olympic events are presenting a smaller number of acidity, due to the increase in the technical quality of the athletes. This has already been verified at the Olympic Games in Rio de Janeiro, which presented $1.2 \%$ less accidents in relation to the London Olympic Games (Engebretsen et al., 2013, Soligard et al., 2017). Huh (2017) also reports that health and safety are priorities for the International Olympic Committee.

The second straight in both tracks was the one that presented the highest number of falls, because it is the moment where the athletes are still next to each other, and from this moment on, the best placed athletes are distanced from the others. In relation to the tracks, we can say that the Belgian track had a higher number of falls, which may be due to the fact that it is a bit narrower and that it has of greater technical difficulty, with the sharpest curves in relation to the track in the Netherlands.

\section{Practical applications}

The study aimed to verify the number of falls of men and women during two rounds of the BMX Supercross World Cup of the Netherlands and Belgium in the year 2017 and check which straight with the greatest number of falls are useful to check which straights need more attention regarding the technical issues of passage on the ramps so that falls are avoided. In addition, it is important to measure whether Supercross tracks differ in degree of difficulty so that more attention is paid to preparatory training before racing.

\section{Conflict of Interest}

The authors declare that they do not have conflict of interests.

\section{References}

Bitencourt v, Amorim S (2006) Bicicross - BMX. In: Dacosta, L. (Org.). Atlas do Esporte no Brasil. Rio de Janeiro: Confef. p. 87-88.

Brøgger-Jensen T, Hvass I, Bugge S (1990). Injuries at the BMX Cycling European Championship, 1989. British Journal of Sports Medicine 24 (4):269-270.

Campillo P, Doremus T, Hespel J-P (2007) Pedalling analysis in bmx by telemetric collection of mechanic variables. Brazilian Journal of Biomotricity 1 (2):15-27. Cowell JF, Cronin JB, Mcguigan MR (2011) Time Motion Analysis of Supercross BMX Racing. Journal of Sports Science and Medicine 10 (2):420-421. eCollection 2011

Cowell JF, Mcguigan MR, Cronin JB (2012) Movement and skill analysis of Supercross Bicycle Motocross. Journal of Strength and Conditioning Research 26 (6):1688-1694. doi: 10.1519/JSC.0b013e318234eb22.

Engebretsen L, Soligard T, Steffen K, Alonso JM, Aubry M, Budgett R, Dvorak J, Jegathesan M, Meeuwisse WH, Mountjoy M, Palmer-Green D, Vanhegan I, Renström PA (2013) Sports injuries and illnesses during the London Summer Olympic Games 2012. British Journal

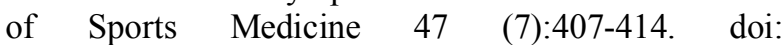
10.1136/bjsports-2013-092380

Guermazi A, Hayashi D, Jarraya M, Crema MD, Bahr R, Roemer FW, Grangeiro J, Budgett RG, Soligard T, Domingues R, Skaf A, Engebretsen L (2018) Sports injuries at the Rio de Janeiro 2016 Summer Olympics: Use of diagnostic imaging services. Radiology 287 (3):922-932. doi: 10.1148/radiol.2018171510.

Heggie TW, Caine DJ (2012) Epidemiology of injury in adventure and extreme sports. Medicine and Sports Science. 58::1-16. doi: 10.1159/000338558

Huh S (2017) How can we reduce injuries and illnesses among athletes during the PyeongChang 2018 Olympic Winter Games? Journal of Exercise Rehabilitation 13 (6):615-616. doi: 10.12965/jer.1735184.592.

Keogh JW, Haakonsen E, ORR R (2017) Literature review: kinematics of the BMX Supercross gate start. Journal of Science and Cycling 6 (1):3-10.

Louis J, Billaut F, Bernad T, Vettoretti F, Hausswirth C, Brisswalter J (2013) Physiological Demands of a Simulated BMX Competition. International Journal of Sports Medicine 34 (6):491-496. doi: 10.1055/s-00321327657.

Mateo-March M, Blasco-Lafarga C, Doran D, RomeroRodríguez RC, Zabala M (2012) Notational analysis of European, World, and Olympic BMX cycling races. Journal of Sports Science and Medicine 11 (3):502-509. eCollection 2012

Rodrigues C (2010) Dicionário de esportes e atividades de aventura: uma proposta de organização de termos e vocábulos. Monografia (Pós Graduação em Atividades e Esportes de Aventura), Faculdade de Educação Física, 


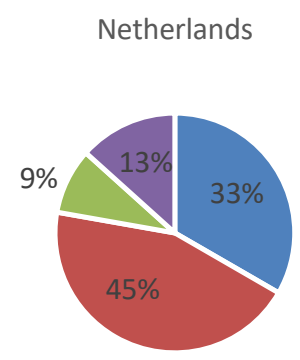

- 1st Straight $=$ 2nd Straight $=$ 3rd Straight $=$ 4th Straight

Figure 1. Percentage of men's falls, separated by straight during the BMX Supercross World Cup in Netherlands.

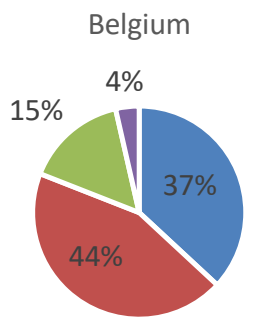

- 1st Straight $=$ 2nd Straight $=3$ rd Straight $=4$ th Straight

Figure 2: Percentage of men's falls, separated by straight during the BMX Supercross World Cup in Belgium.

Netherlands

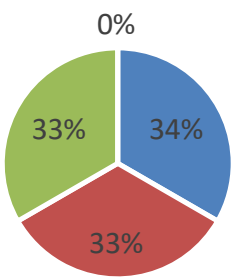

- 1st Straight $=$ 2nd Straight $=3$ rd Straight $=4$ th Straight

Figure 3. Percentage of women's falls, separated by straight during the BMX Supercross World Cup of in the Netherlands.

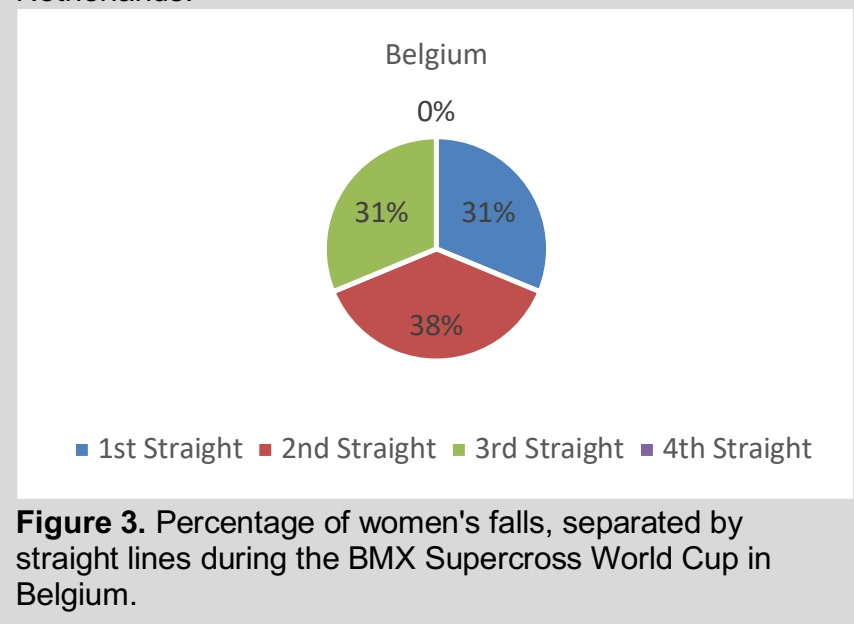

- 1st Straight $=$ 2nd Straight $\|$ 3rd Straight $=4$ th Straight

Figure 3. Percentage of women's falls, separated by straight lines during the BMX Supercross World Cup in Belgium.
Centro Universitário Faculdades Metropolitanas Unidas. São Paulo, 106 p

Soligard T, Steffen K, Palmer D, Alonso JM, Bahr R, Lopes AD, Dvorak J, Grant ME, Meeuwisse W, Mountjoy M, Pena Costa LO, Salmina N, Budgett R, Engebretsen L (2017) Sports injury and illness incidence in the Rio de Janeiro 2016 Olympic Summer Games: A prospective study of 11274 athletes from 207 countries. British Journal of Sports Medicine 51 (17):1265-1271. doi: 10.1136/bjsports2017-097956.

Union Cycliste Internationale (UCI) (2017). BMX Racing Vídeos. available at < http://uci.ch/bmx/videos/>.

Zabala M, Requena B, Sánchez-Muñoz C, GonzálezBadillo JJ, García I, Oöpik V, Pääsuke M (2008) Effects of sodium bicarbonate ingestion on performance and perceptual responses in a laboratory-simulated BMX cycling qualification series. Journal of Strength Conditioning Research 22 (5):1645-1653. doi: 10.1519/JSC.0b013e318181 febe. 